


\section{Humanos sonham com ovelhas reais?}

\section{Do humans dream with real sheep?}

\author{
Igor Alexandre Capelatto' $[3$
}

\section{Resumo}

O presente artigo procura discutir o conceito de real e de imaginário (e assim, se o conceito de realidade seria ou não uma contradição ao conceito de ficção) no cinema, através da filosofia da ficção do filósofo Vilém Flusser; usando como analogia o conto Andróides sonham com Ovelhas Elétricas? do escritor Philip K. Dick e o filme Matrix dos irmãos Wachowski. Qual é o limiar entre a imagem (e aqui inclui-se o som, e em um cinema contemporâneo com novas tecnologias, o tato e olfato) fílmica e realidade dos sentidos dos espectadores?

\section{Palavras-chave}

Flusser; Dick; cinema.

\section{Abstract}

This paper discusses the concept of real and imaginary (and thus the concept of reality would be a contradiction or not of concept of fiction) in film, through philosophy of fiction of Vilém Flusser, using as an analogy the tale Do Androids dream of Electric Sheep? written by Philip K. Dick and Wachowski brothers' Matrix. What is the threshold between the image (and here the sound is included, and in contemporary cinema with new technologies, touch and smell) and filmic reality of the viewers (spectators)?

\section{Keywords}

Flusser; Dick; cinema. 
O engajo cinematográfico da construção de uma suposta realidade (aqui em significado de universo, lugar dos signos, ambiente de sensações) aprisiona os sentidos humanos, com força física à visão e à audição (e em um cinema pós-moderno, com avanços tecnológicos, podemos considerar o tato e porque não o olfato e o paladar), transportando a sensação de estar presente do espectador, por exemplo, em uma sala de cinema (o suposto mundo real), para um universo imagético projetado (o suposto mundo ficcional). A imagem fílmica é um campo no qual as sensações humanas se convertem em imagem virtual e vice-versa. Cria-se uma linha tênue entre a sensação de real ${ }^{2}(e$ entra em debate o conceito de realidade) e a sensação de ficcional (considerando também o pensamento flusseriano que conceitua a "ficção como o fundamento ciência e da ética" (Bernardo et al, 2008, p.143).

Em uma paródia ao avanço tecnológico e os sonhos futurísticos dos seres humanos (o desejo do homem de ser Deus ${ }^{3}$ ) o escritor Philip K. Dick, em seu conto Andróides Sonham com Ovelhas Elétricas? (2014) discute a incompletude humana diante da realidade - para se completar, o homem necessita criar, através de ferramentas tecno cibernéticas, um mundo que se assemelhe àquele que ele "deseja". No universo cinematográfico, os filmes tornam-se representações deste mundo desejado. É o lugar onde o homem se permite assumir como ser ficcional. No entanto é também o lugar onde o homem se aceita como real.

Afinal, o que vemos não seria a representação ficcional dealgo"real"? Mesmoqueaimagem represente na tela uma alusão ficcional (uma história imaginária, cenários e personagens ficcionais), sua construção fora a partir do registro filmico de elementos táteis (atores, objetos cênicos). No conto de Dick, ovelhas elétricas

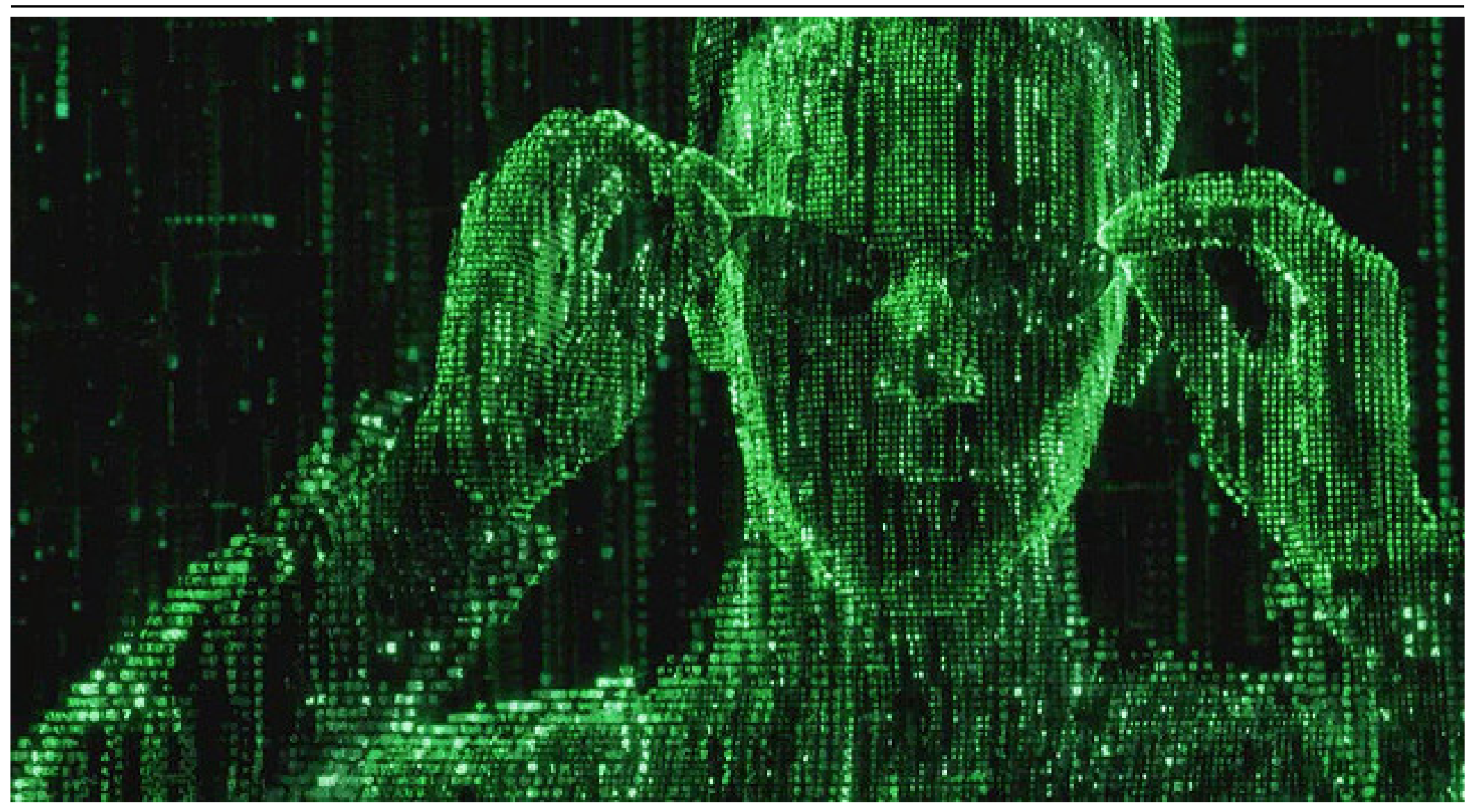

são construídas de forma tão perfeita que não é mais possível diferenciar ovelhas elétricas (e todo tipo de animal elétrico) de ovelhas reais. $O$ que observamos é que a cultura incube de colocar ovelhas elétricas em meio a ovelhas reais sem que as reais percebam que as elétricas não são reais: a imagem fílmica (representação) se assemelha tanto a imagem "real" que a linha que a distingue acaba por dissipar. Nossa formulação mental de imagens e do que possa ser a realidade dos sentidos é enganada pelas imagens projetadas.

Ó, meu Deus - Iran disse suavemente. Ela andou até o engradado, perscrutando seu interior; então ela o contornou, examinando a cabra por todos os ângulos. — Ela é realmente verdadeira? - perguntou. - Não é falsa?

- Absolutamente verdadeira - assegurou ele. - A menos que me tenham me enganado. (Dick, 2014, p. 166)

"Ela é realmente verdadeira?", pergunta Iran, sobre a cabra que ela está vendo no engradado. Esta pergunta é formulada com intuito de questionar se o animal é uma réplica cibernética (uma cabra elétrica) ou um animal natural (verdadeiro em oposição à noção de falso). Mas o que seria falso? Algo que não é real? Falso é aquilo que 
é simulado, manipulados. Para ser manipulado, deve ter substância (palpável ou não), ter forma (imagem representativa). Falso pode ser considerado antônimo de verdadeiro, mas não oposição a real. Pois mesmo para ser um simulacro, deve existir, ser real.

Talvez assim possamos chegar a uma primeira afirmação do que é "ficção". Ficção é algo real à medida que para existir, tem que ter uma imagem representativa. Verdadeira seria a ficção que faz parte da realidade dos sentidos, enquanto que falsa seria a ficção que se permanece no âmbito das imagens, do simulacro (cujos sentidos podem decodificar simbolicamente, mas não fisicamente). As imagens fílmicas são imagens simuladas: a ficção falsa. Mas seriam elas analogia as ovelhas elétricas?

Ovelhas elétricas são animais tangíveis, estão ao nível da realidade dos sentidos, porém são consideradas falsas por não serem naturais. Mas o que seria "natural"? No universo criado por Dick, compreendemos que natural é o ser que é desprovido de mecanismos eletrônicos, mecânicos ou sintéticos. Onde estariam as ovelhas elétricas no universo fílmico? Se considerarmos relações somáticas ${ }^{6}$, podemos dizer que as construções imagéticas reverberam no corpo (da mente para o corpo), constituindo assim uma transposição do simulacro para a realidade dos sentidos. Algo como transformar nossos corpos verdadeiros em corpos elétricos. $O$ espectador torna-se, ao somatizar as imagens fílmicas (emoções subjetivas), uma ovelha elétrica.

Com essa aproximação da sensação de real, o espectador deixa de conceber as imagens fílmicas como representações de uma ficção falsa, pois não há mais o simulacro. O dentro e fora do filme deixa de fazer sentido: não há mais a camada que separa os dois universos: o verdadeiro e o falso. Segundo Flusser (citado por Pelegrini, 2010, p. 85), “a primeira função do cinema é portanto tapar a 'realidade', e a segunda é criar distância entre a pseudo-realidade assim produzida e a pessoa". É como estar na Matrix' (e ter uma certeza absoluta de que ela é real).

A primeira função do cinema é portanto tapar a "realidade", e a segunda é criar distância entre a pseudo-realidade, assim produzida, e a pessoa. Destrói portanto, o universo de duas maneiras: racha-lhe a unidade (opondo a tela à "realidade"), e o afasta (pondo a nós, os espectadores, em oposição ao universo). O cinema é divertido porque destrói o universo. O universo se tornou insuportável na fase atual da civilização tecnológica, porque a sua universalidade consiste na transformação de todas as coisas em instrumentos (Flusser apud Pelegrini, 2010, p.85).

Entre a Matrix e o mundo fora dela existe um sistema de conexão, no qual unem-se corpo e o mundo virtual dos sonhos. Quando se despluga o corpo da Matrix, no instante em que a mente desperta (em consequência desperta o corpo), descobre-se um abismo entre as duas ficções: o mundo pseudoreal e o mundo virtual. Este abismo é constituído pela descontinuidade entre o corpo e a máquina, entre a mente humana e a mente da máquina (sistema), e pela disparidade entre as línguas (os códigos linguísticos usados pelo homem e os códigos usados pela máquina): "O salto de língua a língua, atravessando o abismo do nada, cria no intelecto aquela sensação de irrealidade, tão aparentada à angústia existencial [...]" (Flusser, 2007, p. 59).

Para entender e comunicar-se com a máquina é preciso compreender sua forma de pensar e agir. Para entender os códigos presentes em um filme, é preciso compreender a linguagem que o mesmo se apropria - a gramática cinematográfica, a poética, a narrativa etc. e codificá-la. É na tentativa de superar o abismo entre as línguas que o homem encontra uma possibilidade em compreender como as construções imagéticas transitam para a realidade dos sentidos. As construções imagéticas dialogam através de signos, enquanto a realidade dos sentidos dialogam através do corpo. Segundo Flusser (2011, p.19), "devemos mergulhar em seu abismo, caso almejemos nos reconhecer nele".

Sendo o corpo local de reverberação das construções imagéticas, podemos dizer que esse corpo sendo um canal transmissor de virtualidade, se tornaria assim um corpo falso? Homem se tornando ovelha elétrica: uma representação androide? Esse homem comunicase com a máquina: o espectador se comunica com o filme. Esta relação filme público se estabelece. Mas esse público é capaz de transmitir essa mensagem adiante (ou modificá-la atribuindo novos significados)? Neste processo, o espectador está preparado para participar deste canal de semiose ${ }^{8}$ ?

O espectador precisa conhecer tanto as línguas dos signos provenientes (a sua língua e a língua do filme) quanto as línguas daqueles para quem ele irá transmitir os novos significados. Para que humanos e androides possam se comunicar entre si.

Ao conhecer as múltiplas línguas e assim, as múltiplas culturas, estabelecemos melhor a compreensão do que possa ser ficção. Por haver uma transformação da mensagem (semiose), observa-se outra denominação do que é ficção: é algo imaginário. Ficção pode ser denominada como tudo aquilo que é simbolicamente imaginado: signos. Para tal pressuposição, consideramos a necessidade do homem de se firmar 'real'. Aquilo que 
é automático, como a respiração, por exemplo, pode ser considerado real, enquanto que aquilo é pensado, torna-se ficcional.

Segundo Flusser, a partir das ressignificações, "o homem passa a ser programador da história" (apud Bernardo, 2011, p.2). O espectador vê uma imagem na tela, uma imagem recheada de signos (ele também ouve sons). Sua mente codifica, conforme seus códigos, criando novos signos, e neste processo ele inclui suas percepções, sua cultura, sua imaginação, ou seja, sua ficção. E ele acredita que está falando sobre ovelhas reais, enquanto na verdade esta referindo-se a ovelhas elétricas, uma vez que ele só pode pressupor o que seja uma ovelha real, afinal, ficcionalizando seu discurso e incluindo seus códigos em sua narrativa, ele cria ficção da ficção, distanciando-se cada vez mais do que supostamente poderia ser a "realidade".

"Ainda tenho minha ovelha elétrica [...]" (Dick, 2014, p. 124), diz a personagem, Rick, no conto de Philip K. Dick. Por mais que o status zênite (ápice) seja a aquisição de uma ovelha "verdadeira" ("real"), e que a cultura faça com que ovelhas elétricas se passem por ovelhas reais, o homem ainda se afirma por assumir que sua ovelha é elétrica. "O cinema divertido por duas razões fundamentais: diverte a atenção daquilo que chamamos, normalmente, de 'realidade', e converte o homem de participante em espectador" (Flusser apud Pelegrini, 2010, p.85).

Uma vez que o homem não consegue se posicionar cartograficamente, ele não sabe se está nas construções imagéticas ou na realidade de sentidos. Por não serem precisas a noções de realidade imagética e realidade de sentidos, o homem se torna estrangeiro: ele é estranho "dentro do filme" e é estranho "fora do filme".

No mundo contemporâneo torna-se comum o homem se afirmar pelo fato de sua ovelha ser elétrica: o espectador que se sente presente ao se assumir parte da imagem fílmica. Segundo Flusser (2011, p.52), "estrangeiro (e estranho) é quem afirma seu próprio ser no mundo que o cerca".

Quando Flusser afirma que "o homem é estrangeiro no mundo", ele quer dizer que assim o homem também é estrangeiro nas arquiteturas que ele produz. Ele é estrangeiro em seus shoppings centers, nos seus clubes e na sua própria casa. O homem se torna estrangeiro em sua própria vida. E se torna turista ao revisitar sua própria história. E por isso cria filmes (ou qualquer outra forma artística): para reforçar o fato de que sua vida não passa de uma ficção.

É senso comum afirmar que o homem pertence a uma sociedade e que essa sociedade pertence ao mundo. Mas este mundo não o pertence - e não quer abrigá-lo. $\mathrm{O}$ homem se sente excluído deste mundo. Torna-se um estranho na sala de cinema, descobrindo que sua vida não passa de uma simulação. Um mundo que o engana fazendo-o crer que ovelhas elétricas são reais - quimera da realidade.

Simular a realidade é fazer poesia. Quem simula a realidade é poeta. $O$ poeta encontra as mais diversas formas para criar o mundo à sua maneira. Ele simula uma realidade e traz na poesia (e na arte como um todo) o mundo que ele deseja. O leitor da poesia se sente tocado e passa a viver este mundo. A poeisis é o mundo em que o homem não é estrangeiro. Ele só se torna turista neste mundo se ele se fizer estranho, se ignorar a poesia.

A dúvida da realidade faz o poeta buscar hipóteses e criar seus próprios mundos. Mas quando confrontamos as hipóteses de nossas teses muitas vezes acabamos duvidando da nossa dúvida. E criamos nosso próprio paradoxo. Surge a dúvida da dúvida. E surge o antipoeta, que reforça a incerteza na poesia transformando o mundo em um anti-mundo: opondo-se as realidades. Não seria o filme (a arte de modo geral) este anti-mundo?

"A dúvida da dúvida é a antipoesia" (Flusser, 2011, p.88). O antipoeta faz da poesia a incerteza da vida em por contradição, na contemporaneidade, se faz poeta, pois a vida contemporânea se opõe a poesia. E antipoesia se torna o filme realista: tão real que esquecemos que é ficção. Tão real que chamamos de documentário e abstraímos o fato de que um documentário tem por excelência o olhar de um cameraman, de um diretor, o recorte da realidade por uma perspectiva poética e ficcional.

Neste mundo ficcional o homem precisar se firmar e atribuir uma conotação de "realidade". Mas qual o sentido de realidade que estamos apreciando? Talvez o homem seja um turista acidental no mundo. "O homem é um ente essencialmente perdido e, quando se dá conta, procura encontrar-se" (Flusser, 1998, p.3). Mas ele não definiu qual realidade cartográfica ele quer seguir. $O$ filme termina, mas a antipoesia continua a vagar.

\section{Referências}

BERNARDO, Gustavo; FINGER, Anke K.; GULDIN, Rainer. Vilém Flusser: uma introdução. Annablume, 2008.

DA SILVA FILHO, Luiz Marcos. Sobre o Fundamento Voluntarista da Política em Agostinho. Colóquio de História Medieval. Leme/UFMG, 23, 2012.

DICK, Philip K. Androides Sonham Com Ovelhas Elétricas? Editora Aleph, 2014

O Caçador de Androides. Rio de Janeiro: F. Alves, 1989. 
FLUSSER, Vilém. Da ficção. In: Matraga, n. 13, 2000 [on-line]. Disponível em: <http://www.pgletras.uerj.br/ matraga/matraga13/matraga13flusser.pdf $>$ Acesso em 23 set. 2014.

\section{Fenomenologia do brasileiro.}

Busca de um Novo Homem. Rio de Janeiro: UERJ, 1998.

Annablume, 2007.

\section{Natural:mente. São Paulo:}

Língua e realidade. São Paulo:

Annablume, 2011.

IRWIN, William. Matrix: bem-vindo ao deserto do real. São Paulo: Madras, 2003.

PELEGRINI, Milton. Imagens técnicas e distopias. A sociedade programada no pensamento de Vilém Flusser. Significação-Revista de Cultura Audiovisual, v. 37, n. 33, pp. 79-89, 2010.

SILVA, Vítor. Teoria da Literatura. Coimbra: Almedina, 1986.

SILVER, Joel. Matrix. [Filme-vídeo]. Produção de Joel Silver. Direção de Andy e Lana Wachowski. Estados Unidos, 1999. $136 \mathrm{~min}$. color. son.

\section{Notas}

1 MestreeDoutorandoem Multimeios pela Universidade Estadual de Campinas (UNICAMP - Instituto de Artes, Rua Elis Regina $n^{\circ} 50$, Cidade Universitária "Zeferino
Vaz", Barão Geraldo, Campinas-SP, Brasil, CEP: 13083854). E-mail: capuccinoprod@gmail.com

2 Segundo Vilém Flusser (2000, on-line), essa é uma ficção chamada "realidade dos sentidos".

3 Senellart citado por Da Silva Filho (2012. p.27).

4 Andróides Sonham com Ovelhas Elétricas? foi lançado no Brasil em 1989 sob o nome de OCaçador de Andróides, devido ao filme homônimo de Ridley Scott baseado neste conto e em 2014 tem uma versão revisada e publicada pela Editora Aleph com o nome original do conto de Dick. O livro, tanto quanto o filme tornaramse ícones de uma cultura pop, tanto literária quanto cinematográficas, por abordarem questões filosóficas existenciais através de uma narrativa teen e cult.

5 Disponível em <http://www.priberam.pt/dlpo/falso> Acesso em 17 jun. 2014.

6 Sôma em grego significa corpo. Relações Somáticas são correspondências da mente (psiquê) no corpo. $\mathrm{O}$ ato de somatizar o simulacro: sentir fisicamente (no corpo) as sensações causadas subjetivamente pelas imagens simbólicas (talvez possamos fazer uma analogia semiótica e dizer que somatizar é transformar signos em símbolos).

7 "Nas telas do cinema, Matrix é um mundo de sonhos gerado por computador, o qual, por meio de uma realidade virtual, simula o nosso mundo como é hoje" (Irwin, 2003). Matrix (Matrix, Andy e Lana Wachowski, 1999). é primeiro filme de uma trilogia criada pelos irmãos Wachowski em 1999.
8 Semiose: 'todo processo em que algo (veículo significativo) funciona como sinal de um designatum (aquilo a que o sinal se refere), produzindo um determinado efeito ou suscitando uma determinada resposta (interpretante) nos agentes (intérpretes) do processo' (Silva, 1986, p.181). 